Article

\title{
A Linear Brushless Direct Current Motor Design Approach for Seismic Shake Tables
}

\author{
Ozgur Ustun ${ }^{1,2, *, t, \neq}$, Omer Cihan Kivanc ${ }^{2,3, \mp(1)}$ and Mert Safa Mokukcu ${ }^{4, \ddagger}$ \\ 1 Department of Electrical Engineering, Istanbul Technical University, 34469 Istanbul, Turkey \\ 2 Mekatro Mechatronics Systems R\&D Co., ITU Ari Teknokent, ARI-2/B, 34469 Istanbul, Turkey; \\ cihan.kivanc@okan.edu.tr \\ 3 Department of Electrical and Electronics Engineering, Istanbul Okan University, 34959 Istanbul, Turkey \\ 4 Sherpa Engineering, 333 Avenue Georges Clemenceau, 92000 Paris, France; m.mokukcu@sherpa-eng.com \\ * Correspondence: oustun@itu.edu.tr or oustun@mekatro.com; Tel.: +90-212-285-3338 \\ + Current address: Department of Electrical Engineering, Istanbul Technical University, 34469 Istanbul, Turkey. \\ $\ddagger$ These authors contributed equally to this work.
}

Received: 27 September 2020; Accepted: 26 October 2020; Published: 29 October 2020

\begin{abstract}
The progress in material and manufacturing technologies enables the emergence of new research areas in electromagnetic actuator applications. Permanent magnet (PM) linear motors are preferred to achieve precise position control and to meet the need for high dynamic forces in the seismic shake tables that are used in analyzing reactions of structure models. The design approaches on the linear motors used in the seismic shake tables may vary depending on the desired force, stroke and acceleration values. Especially, the maximum width, the maximum depth, the maximum linear motor length in longitudinal direction and the maximum travelling distance parameters are the primary design criteria in seismic shake table drive systems. In this paper, a design approach for a linear PM brushless direct current (BLDC) motor with high force/volume, force/weight and force/input power ratios is developed. The design was analyzed using two-dimensional (2D) and three-dimensional (3D) finite element method (FEM) approaches through the ANSYS Maxwell software. The mathematically designed linear BLDC motor was manufactured and subjected to displacement, acceleration and force tests that are used in seismic analyses. The results of the experimental tests validate the convenience of the proposed design approach and the selected parameters.
\end{abstract}

Keywords: linear brushless direct current motor; finite element analysis; seismic shake table; special electric machines

\section{Introduction}

Linear motors are becoming increasingly favored in industry due to their simple structure and manufacturing [1,2]. They are capable of high acceleration, precise positioning, low-maintenance operation and long life [3]. Linear BLDC motors have been used for applications ranging from rocket positioning and health operations to seismic table actuators [4,5]. Especially, high speed and precision, fast response and zero backlash capabilities of PM linear motors are becoming considerably more important in seismic shake table actuator applications. The goal of a seismic vibrator is to exert a controlled time-varying high dynamic force on the structure [6]. In a basic vibrator, this force is provided by driving an actuator that moves a payload with respect to a base plate, which is in contact with the ground [7]. In contrast to hydraulic actuators, the linear electric motor performs equally well over the whole frequency range, especially at the low frequencies, making a small amount of signal distortion and can track various force-time profiles [8]. The usage of linear electric motors in seismic 
shake tables has enormously increased in the last years thanks to the aforementioned advantages [9]. Particularly, linear BLDC motors with high force densities come forward by having the qualities to meet the requirements of earthquake simulators. Modular structure of these motors is available with features including extendable stroke and increased thrust force. Thus, seismic waves that may have various displacement characteristics can be simulated [6,9].

In recent years, the studies on linear motors have been concentrated on motor design topologies and control methods [10-12]. However, selection of the design criteria and approach is essential for different types of linear motor applications $[13,14]$. The design approach may vary depending on the application, force/weight and force/volume ratios as performance measures and the variations in the displacement distance. As is known, efficiency is no longer a goodness measure for these type of motors because of low-speed applications. Various studies in the literature show different design targets. A linear flux switching permanent magnet with short double-side primary mover is proposed in [15]. The motor is particularly well suited to long stator applications including urban rail transport. An optimization approach, namely the sequential quadratic programming method, for the maximization of the thrust force and the minimization of force ripples in brushless PM motor, is proposed in [16]. By using this method, the normalized force ripple is reduced by $7.7 \%$ and the thrust force increase is $12.88 \mathrm{~N}$ in comparison with the design that is not optimized. To achieve the required thrust and optimal sinusoidal magnetic field, in [17], the authors altered the winding pitch and the current switching sequence, gaining required thrust, indicating that the harmonics and end effects of a linear motor are equal. The main aim is to obtain optimal sinusoidal magnetic field and required thrust. Some special phenomena involving transverse edge effect and end effect saturation of back iron are analyzed in [18]. The study includes the computation of the saturation by simple equations and iterative methods using Duncan model. In [19], a PM linear synchronous motor for ropeless elevator system is developed. The long stator double-sided slotted iron core type permanent magnet linear synchronous motor with fractional slot winding is selected for the superior performance using finite element analysis (FEA). In [20], a rotary motor with ball-screw table is retrofitted into a sub micro-meter stage. Moreover, a comparison between conventional drive and linear direct drive is conducted with sub-micron feedback. In [21], an alternative solution is formulated, defining the commutation as an optimization criterion for ironless linear motors, wherein it is shown that. due to the deviations from the design parameters, there are various parasitic forces and torques for which the classical commutation could not compensate. In [22], a $320 \mathrm{~W}, 5 \mathrm{~m} / \mathrm{s}$ and four-pole permanent magnet based linear synchronous machine is designed and manufactured. The design deals with conventional hand calculations followed by design fine-tuning and analysis using standard FEM packages. In [23], a transverse flux reluctance motor circuit-field model is developed. The proposed model is based on the variable equivalent air gap permeance concept and fully considers the iron core saturation through FEM analysis results. Furthermore, a simplified version of the model is introduced. The flux linkage-current characteristics at the aligned and unaligned positions and peak thrust are solely utilized. In [24], a two-dimensional analytical model is presented for calculation of the electromagnetic field for linear planar PMSMs with slotless stator structure. A 2D analytical model with the finite permeability of the cores is considered. In [25], the proposed method accounts for the varying input voltage of both unloaded and loaded PM BLDC motor using experimental cutting force data to simulate dynamic effects. In addition, the effects of applied loading are demonstrated in this study and examined to assist in the selection of operating parameters.

However, the state-of-the-art lacks the design approaches in accordance with the criteria suitable for use in seismic shake tables. For this reason, a linear BLDC motor design approach was developed using fractional slot concentrated type winding. The targets determined in the design of the linear BLDC motor can be enumerated as greater than $2.5 \mathrm{kN}$ continuous force, $0.5 \mathrm{~m} / \mathrm{s}$ speed and $1600 \mathrm{~mm}$ travel distance. In addition, it was aimed to have high force/volume and force/weight ratios and high efficiency by the designed linear BLDC motor to fulfill shaker table application requirements. Baseline design parameters were determined and basic sizes were calculated in accordance with the 
proposed approach developed in the study. Then, the design outputs were compared to the target values for thrust, force and efficiency. The designs were assessed based on the thrust force quality, weight, efficiency and ease of manufacture and the most appropriate design configuration. The models were analyzed using ANSYS Maxwell FEM software. Then, a specially designed test bed was used to perform experimental studies on the seismic shake table. The displacement, speed and acceleration tests of the linear BLDC motor were performed regarding to the earthquake parameters measured in the 1999 earthquake in Kocaeli, Turkey. Recent seismic activities in Northern Anatolian region imply the importance of the study [26], which shows that simulation and testing of scale models of structural components and systems are essential for such research areas. As a result of the experimental studies, the validity and effectiveness of proposed design approach for linear BLDC motor are discussed thoroughly and the resulting contribution is verified.

\section{Design Approach}

In this study, the main output parameter is the maximum dynamic force production. To provide the proper dynamic force to seismic shake table, the force density of linear motor must be defined adequately. The starting force (zero speed) densities of PM linear and rotating machines (for rotating motor assuming shear force in air gap area) vary within $10-70 \mathrm{~N} / \mathrm{cm}^{2}$ depending on the PM materials and locked armature (or magnet assembly) current values. Of course, these values are for short circuit (no motion) operations, and, most of the time, actual electric sources and driver transistors may not cope with those extreme values. In practice, the terminal current must be limited and the operation is permitted only for short time intervals. In the study, considering the DC source constraints, the dimension constraints of the motor and heating effects, a 3-kN dynamic thrust force and $150-\mathrm{cm}^{2}$ active motor area (thrust force produced in the active air gap area, i.e., area below the armature), the dynamic force density is predetermined as $20 \mathrm{~N} / \mathrm{cm}^{2}$.

The other design criterion of the linear motor is the electrical time constant. Recently, sub-fractional slot-pole type permanent magnet motors rose to prominence due to their high force (torque) production capabilities. However, because of sub-fractional concentrated winding structure, the motors have relatively higher winding inductance values, i.e., large electrical time constants, which hamper fast force production. Depending on the current density, losses and slot area constraints, the winding resistance cannot be made higher than a certain limit. Using all-teeth-wound winding topology is causing a lower value of winding inductance while alternate-teeth-wound structure results in higher winding inductance [27]. In this study, the application requires a fast acting, dynamic force production to simulate the mentioned earthquake movements. Therefore, a linear motor design with relatively lower winding inductance is selected intentionally, resulting in all-teeth-wound armature structure having half of the inductance value of alternate-teeth wound motor.

It is of crucial importance to determine geometrical, mechanical and electrical constraints that are caused by the unique structure of the seismic shaker accurately while creating the design approach. These constraints play an important role in the assignment of the initial values of the design [28]. The linear slotted motor topology is used in high-force applications. The reason for this is that the iron core can stimulate higher force by concentrating the magnetic field created by the windings. To obtain high force density, sizes and materials have been optimized [29]. Thus, a high-quality electric steel with higher relative magnetic permeability is used to form the primary structure. It is expected that the ferromagnetic core provokes high magnetic flux density with low magnetic field intensity, and the iron loss is consequently low. The designed back iron has to be manufactured from high magnetic permeability and low-carbon cold-rolled soft steel. To specify the thickness of the back iron, some ampere-turn loss is permitted due to the saturation to avoid a bulky design. In other words, a non-saturated back iron results in heavier design. It is aimed to keep the losses at a minimum level by using M24/29G type material of high quality in the structure which will form the primary yoke and teeth. Moreover, it is important that the core ampere-turn loss must be a small percentage of air 
gap ampere-turn for enhanced performance. To obtain higher force production, N35 type rare-earth PMs with higher energy density are used.

The maximum stroke force is determined by means of the required maximum acceleration for a specific payload, i.e., the moving mass of the system plus the mass of tested component. The open loop tests show that the damping of the system can be assumed as $10 \%$ of the total force. Thus, by using the linear motion equation (Equation (1)), the maximum force is calculated as $2.5 \mathrm{kN}$ for $460 \mathrm{~kg}$ of total moving mass.

$$
F_{e}=m_{L} a+\beta v
$$

where $F_{e}, m_{L}, a, \beta$ and $v$ are the stroke force, payload, acceleration, damping coefficient of the system and motion speed, respectively. Although there are rubber and spring stoppers in the seismic shake table, the spring component of the motion equation is assumed nearly zero, because the spring action is not included in the shaker motion.

The initial design parameters are shown in Table 1. The crucial point taken into consideration in the sizing of the magnets is to prevent the increase of short-circuit flux lines between the two adjoining inverse polarized magnets by leaving a gap or a non-magnetic spacing between the magnets. Thus, the flux lines of PMs can be directed to the airgap. For this reason, the magnet embrace factor is determined as $85 \%$ according to the number of poles selected for no-load speed determined for the seismic shake table. The calculation of the flux concentration factor, $C_{\phi}$, for the linear BLDC motor is shown in Equation (2).

$$
\begin{gathered}
C_{\phi}=\frac{A_{m}}{A_{g}}=\frac{\tau_{m} L_{a}}{\tau_{p} L_{a}} \\
H_{m}=-\left[\frac{1}{\mu_{0}} \frac{g}{d_{m}} \frac{A_{m}}{A_{g}}\right] B_{m}
\end{gathered}
$$

where $\tau_{m}, \tau_{p}, A_{m}, A_{g}, \mu_{0}, d_{m}, L_{a}$ and $B_{m}$ are magnet width, pole pitch, magnet area, gap area, permeability, magnet depth, magnet length (perpendicular to the plane) and magnet flux density, respectively. The flux concentration factor is calculated as 0.8772 . The calculation of the $H_{m}-B_{m}$ curve is shown in Equation (3) [30]. The tooth, core and yoke ampere-turn losses are neglected during calculations. The intersection of the curve with the PM operation line yields approximately $1.08 \mathrm{~T}$ by taking structural dimensions and material features into account. $A_{g}$ is assumed slightly larger than $A_{m}$, by the factor of $10 \%$ due to practical issues. The calculation of flux-per-pole, $\phi_{p}$ is shown in Equation (4) [31].

$$
\phi_{p}=B_{m} \tau_{m} L_{a}
$$

Table 1. Initial design parameters.

\begin{tabular}{cc}
\hline Parameter & Value \\
\hline Supply Voltage $\left(V_{d}\right)$ & $36 \mathrm{~V}$ \\
Maximum Targeted Force $\left(F_{\max }\right)$ & $2.5 \mathrm{kN}$ \\
Motion Speed $(v)$ & $0.6 \mathrm{~m} / \mathrm{s}$ \\
Number of Phase $\left(N_{p h}\right)$ & 3 \\
Number of Magnet Poles Per Three Phase Windings $\left(N_{m}\right)$ & 6 \\
Number of Slots-Per-Pole-Per-Phase $\left(N_{s p p}\right)$ & 0.5 \\
Number of Slots-Per-Phase $\left(N_{s p h}\right)$ & 4 \\
Slot/Pole Ratio $\left(N_{s p}\right)$ & 1.5 \\
Air Gap Length $(g)$ & $1 \mathrm{~mm}$ \\
Magnet Length $\left(L_{a}\right)$ & $80 \mathrm{~mm}$ \\
\hline
\end{tabular}

As it is seen, the flux per pole value is determined depending on the flux density. The demagnetization characteristic is obtained out of $H_{m}-B_{m}$ curve according to the operating 
point $\left(B_{m}=-10.027 \times 10^{-6} H_{m}\right)$ and is chosen as $1.1 \mathrm{~T}$. The tooth flux density, $B_{t}$, is obtained using Equation (5).

$$
B_{t}=\frac{\phi_{p}}{N_{s p} L_{a} w_{s b}}
$$

where $w_{s b}$ is the tooth width. The value of $w_{s b}$ is targeted as $7.7 \times 10^{-3} \mathrm{~m}$ and the value of $B_{t}$ is calculated as $1.904 \mathrm{~T}$ which can be provided by high quality steels. Flux density at back-iron, $B_{b i}$, the tooth flux density in the core, $B_{y o k e}$, and air gap flux density, $B_{g}$, are calculated, respectively, in Equations (6)-(8).

$$
\begin{aligned}
B_{b i} & =\frac{\phi_{p} / 2}{L_{b i} d_{b i}} \\
B_{\text {yoke }} & =\frac{\phi_{p} / 2}{L_{a} d_{\text {yoke }}} \\
B_{g} & =B_{m} C_{\phi}
\end{aligned}
$$

where $L_{b i}$ is the back-iron length. In Equation (6), the flux density at back-iron, $B_{b i}$, is calculated depending on the depth of back-iron, $d_{b i}$ value. $d_{b i}$ value is taken as $5 \times 10^{-3} \mathrm{~m}$ and calculated as $B_{b i}, 2.2$ T. $d_{\text {yoke }}$ value stands for the depth of yoke and is chosen as $25 \times 10^{-3} \mathrm{~m}$. $B_{\text {yoke }}$ is calculated as $0.44 \mathrm{~T}$, and the $B_{g}$ value is calculated as $0.96492 \mathrm{~T}$. In Equation (10), the maximum back-emf value is calculated according to the distribution factor, $k_{d}$.

$$
\begin{gathered}
k_{d}=\frac{\sin \left(N_{s p p} \theta_{s e} / 2\right)}{N_{s p p} \sin \left(\theta_{s e} / 2\right)} \\
E_{\text {max }}=2 N_{m} k_{d} k_{p} k_{s} B_{g} L_{a} n_{s} N_{s p p} v \\
E_{\text {max }} I=F v
\end{gathered}
$$

where $\theta_{s e}, k_{c} g, k_{p}, k_{w}, k_{s}$ and $n_{s}$ are slot pitch as radian converted from linear to rotational, effective air gap, pitch factor, winding factor, skew factor and number of turns in a slot, respectively. The slot pitch in Equation (9) is chosen as $120^{\circ}$ and the $k_{d}$ value is calculated as 1.155 . In addition, the pitch factor is taken as 0.66 and the winding factor as 1 , which is close to unit value for this type of motor.

The $E_{\max }$ value, which is defined for the maximum allowed speed, is obtained as $33.6 \mathrm{~V}$ in Equation (10). The necessary expression for the value of force is shown in Equation (11). Although the velocity is not a design parameter, it is considered to calculate the proper value of force coefficient. Currents up to $45 \mathrm{~A}$ are aimed with 2.4-mm diameter wire chosen in Equation (11), and the value of power is calculated as $2.5 \mathrm{kN}$. $L_{s}$, slot leakage inductance, $L_{g}$, gap leakage inductance, $L_{e}$, end turn inductance, $L_{p h}$, and the total leakage inductance values are calculated, respectively, in Equations (12)-(15).

$$
\begin{gathered}
L_{s}=N_{s p h} n_{s}^{2}\left[\frac{\mu_{o} d_{s} L_{a}}{3 w_{s b}}+\frac{\mu_{o} d_{t} L_{a}}{\left(w_{s o}+w_{s b}\right) / 2}\right] \\
L_{g}=\frac{3 \mu_{o} L_{a} N_{s p h} \tau_{c}}{g+l_{m} /\left(\mu_{r} C_{\phi}\right)} \\
L_{e}=\frac{N_{s p h} \mu_{o} \tau_{c} n_{s}^{2}}{2} \ln \left[\frac{\tau_{c} \sqrt{\pi}}{\sqrt{2 A_{s}}}\right] \\
\Sigma L_{p h}=L_{s}+L_{g}+L_{e}
\end{gathered}
$$

where $d_{s}, d_{t}, w_{s o}, g_{e}, \mu_{r}, \mu_{r} \mu_{0}, \tau_{c}, l_{m}$ and $A_{s}$ are tooth length, pole shoe length, slot opening, effective air gap, relative permeability, load line curve, coil pitch, magnet depth and slot cross-sectional area, respectively. The dimensions used for slot sizing are shown in detail in Figure 1. In Figure 2, the details of the winding structure are presented. A typical all-teeth-wound linear motor armature is implemented by using twelve windings, i.e., a phase winding contains four series-connected coils. 
MMF distribution has ideally a rectangular waveform, but, in practical motors, the sharp edges of the waveform are rounded due to non-ideal effects of magnetic circuit structure. Using Equations (12)-(15), the slot leakage inductance is obtained as $0.92 \mathrm{mH}$, the gap leakage inductance as $0.297 \mathrm{mH}$ and the end turn inductance as $0.216 \mathrm{mH}$. In addition, the phase resistance, $R_{p h}$, value is obtained as $0.0365 \Omega$. The time constant of motor armature windings is found as $39.2 \mathrm{~ms}$ which is adequate for fast dynamic force production. Naturally, the time constant can be decreased via a series connected forcing resistor and increased terminal voltage, enabling fast force responses. However, the power source limits the latter approach. The fundamental dimensions of the linear BLDC motor are given in Table 2. Furthermore, the back-iron is $80 \mathrm{~mm}$ thick as the primary is chosen to have a thickness of $80 \mathrm{~mm}$, length of $182.5 \mathrm{~mm}$ and height of $25 \mathrm{~mm}$. The primary (i.e., armature) is chosen to be $182.5 \mathrm{~mm}$ long and $80 \mathrm{~mm}$ thick to form eight magnets long and two magnets vertically that are used as poles. The most decisive factor of linear motor sizing is due to the standard available permanent magnet dimensions on the market, as well as the requirements of application. To complete the whole primary with 12 stator teeth, the tooth thickness is chosen as $7.5 \mathrm{~mm}$. From this $7.5 \mathrm{~mm}$, if slots are taken $7.7 \mathrm{~mm}$ long and $80 \mathrm{~mm}$ thick, slot area for windings can be calculated as $130 \mathrm{~mm}^{2}$. For fitting windings in the slots, 2.4-mm diameter wire is chosen and there are 20 conductors in one slot.

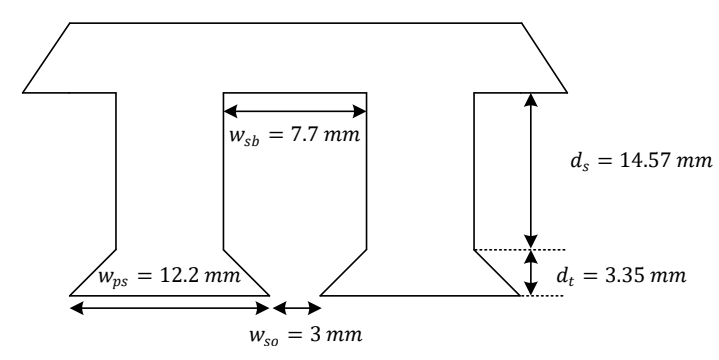

Figure 1. Slot dimensions on armature segment.

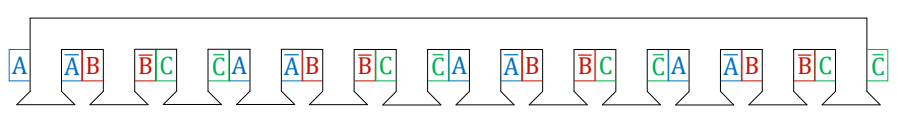

(a) Winding layout of armature.

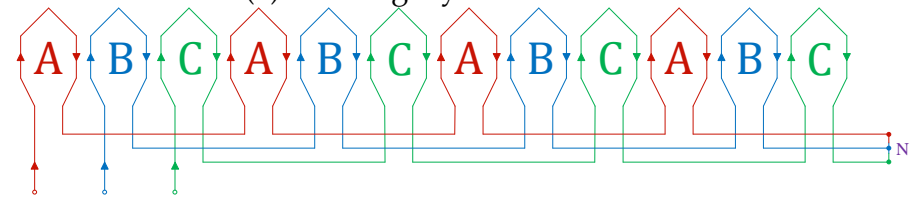

(b) Winding diagram.

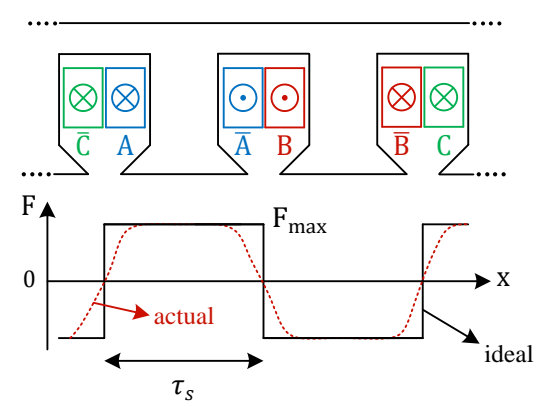

(c) MMF distribution of armature.

Figure 2. Winding structure and MMF distribution of armature. 
Table 2. Fundamental parameters of designed linear BLDC motor.

\begin{tabular}{cccc}
\hline Linear BLDC Motor Part & Length & Thickness & Height \\
\hline Primary & $182.5 \mathrm{~mm}$ & $80 \mathrm{~mm}$ & $25 \mathrm{~mm}$ \\
Back Iron & $1590 \mathrm{~mm}$ & $80 \mathrm{~mm}$ & $5 \mathrm{~mm}$ \\
Magnets & $20 \mathrm{~mm} \times 65 \mathrm{~mm}$ & $80 \mathrm{~mm}$ & $5 \mathrm{~mm}$ \\
Slot & $7.7 \mathrm{~mm}$ & $80 \mathrm{~mm}$ & $15 \mathrm{~mm}$ \\
\hline
\end{tabular}

\section{Electromagnetic Analysis and Results}

A linear BLDC motor design involves a number of assumptions and constraints, where the final design parameters are generally obtained by using the FEM package in the Cartesian coordinates [32]. The magnetic material properties are input to the software including their nonlinearities. By means of automatic mesh generation, the vector potential values are calculated for the different motor parts. The current sheet $(J)$ in the windings located in the slots is,

$$
\vec{J}(t)=J(t) \vec{k}
$$

For 2D magnetic field analysis, the flux density, $\vec{B}$, and field intensity of $\vec{H}$ are related as follows,

$$
\vec{H}=\frac{1}{\mu} \vec{B}-\frac{1}{\mu} \overrightarrow{M_{0}}
$$

where $\mu$ and $M_{0}$ are the magnetic permeability of the medium and the magnetization vector of the PMs, respectively. The magnetic properties of the PMs and the back iron, which is used for transferring the flux between PMs, are single values. Thus, the Poisson's nonlinear equation is satisfied as,

$$
\frac{\partial}{\partial x} \frac{1}{\mu} \frac{\partial A}{\partial x}+\frac{\partial}{\partial y} \frac{1}{\mu} \frac{\partial A}{\partial y}=-\left(J+J_{m}\right)
$$

where $A$ and $J_{m}$ are the vector potential and the current density, corresponding to the magnets. $J_{m}$ is given as follows,

$$
J_{m}=\operatorname{rot}_{z}\left(\mu^{-1} \overrightarrow{M_{0}}\right)=\frac{\partial\left(\mu^{-1} \overrightarrow{M_{0 y}}\right)}{\partial x} \frac{\partial\left(\mu^{-1} \overrightarrow{M_{0 x}}\right)}{\partial y}
$$

The calculated longitudinal force can be found by using the volumetric integral of the vector product of the current sheet, $J$, and the flux density, B, as given in Equation (20).

$$
\vec{F}=\int_{v} \vec{J} \times \vec{B} \cdot d V
$$

By using FEM, the effect of each parameter on the dynamic performance of the motor is investigated. If the output dataset is considered in Section 2, all calculations are well suited for the requirements of the seismic shake table driving. After completing the analysis of the designed linear BLDC motor, a detailed electromagnetic FEA was made to provide proper data to manufacturing process. A two-dimensional magnetic analysis using Ansys Maxwell was implemented by means of a 2D model of the designed motor, which is shown in Figure 3. 2D FEA shows that the optimized motor has admissible magnetic flux airgap density (approximately $0.8 \mathrm{~T}$ ) that allows the proper force production with the back-iron fully covered.

Afterwards, as the 2D model was built to validate the overall design, the sketch of 3D linear BLDC motor, which is shown in Figure 4, was created by using a physical modeling environment. Moreover, a 3D magnetic analysis using ANSYS Maxwell was performed with an adaptive mesh option, which is presented in Figure 5. To have realistic solutions, all parts used for assembly were taken into account according to their magnetic properties. Finally, the coils were sketched and the model was prepared for FEA. In total, 148,332 elements were used for FEA calculations. In the motion setup, to find the 
motion performance of the motor, a sinusoidal function for speed is given for having the motor moves until the position of $338 \mathrm{~mm}$ and goes back to the initial state to define the motion mechanism of the motor. In the analyses, the motor speed was set as $0.6 \mathrm{~m} / \mathrm{s}$.

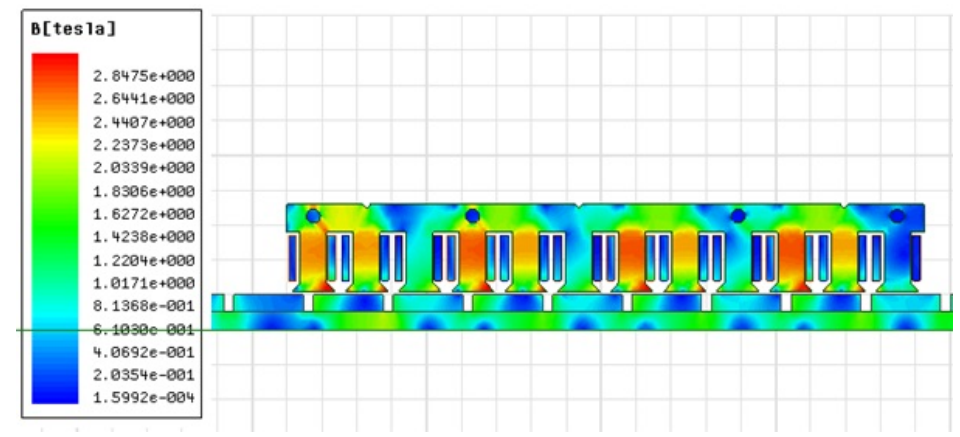

Figure 3. 2D magnetic field density.

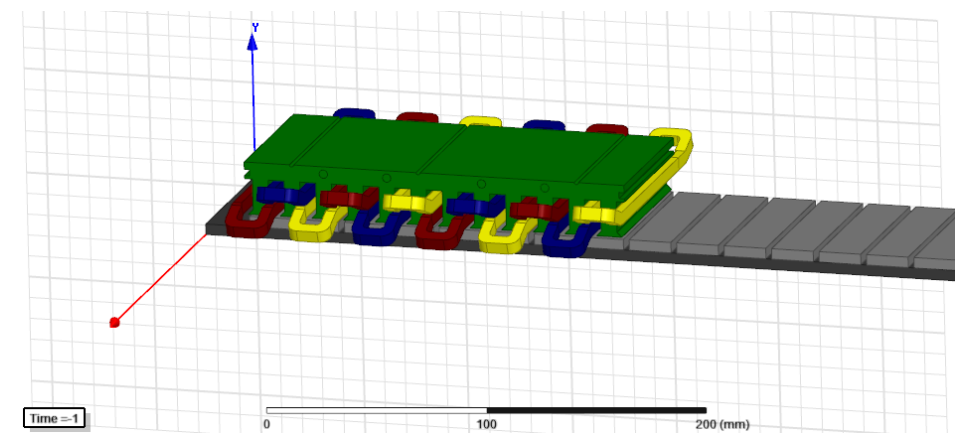

Figure 4. 3D FEA model in ANSYS Maxwell.

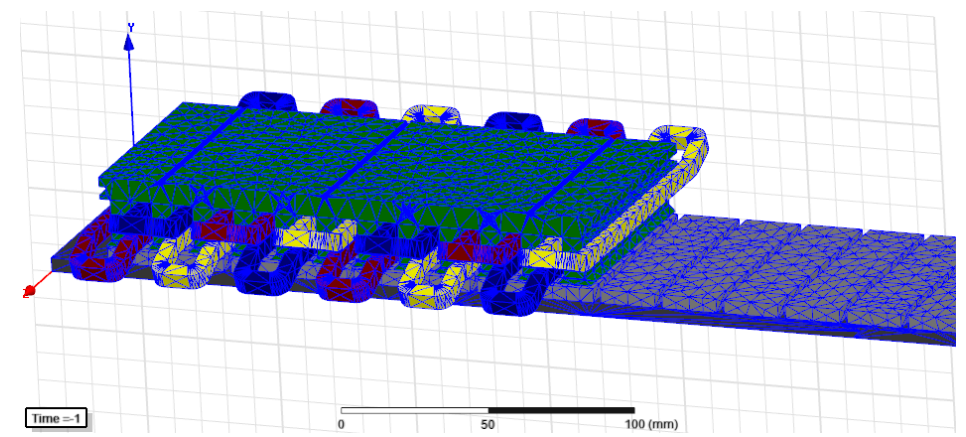

Figure 5. Mesh drawing of FEA model.

In Figure 6, the armature teeth have a little more than $2.5 \mathrm{~T}$ flux density, which implies the presence of saturation. As can be seen from the magnetic flux density, a heavy saturation occurs in the back iron. This shows that the iron losses are minimal. With the advantage of low iron losses, the efficiency reaches high values. In addition, it shows that the core loss is not very high as in other parts of primary, i.e., armature, as there is not much saturation. The efficiency value is obtained as $93.2 \%$ in the analyses for continuous armature motion. After having the magnetic field distribution analysis, the thrust force vs. time graph is taken into consideration, as shown in Figure 7. The analyses reveal that the maximum force that can be produced by the motor is approximately $2.5 \mathrm{kN}$. It is observed that the attraction force between armature can reach 7-10 times the stroke force. The manufacturing of the linear electric motor was carried out by mounting 160 magnets on a 1590-mm back-iron which defines the course of motion. The total length of the motor was selected to take into account future studies. On the other side, longer magnet assembly allows evaluating the motor performance for continuous motion. To counteract the attraction force on the bearing, the bearing system was chosen to withstand forces up to $25 \mathrm{kN}$. 


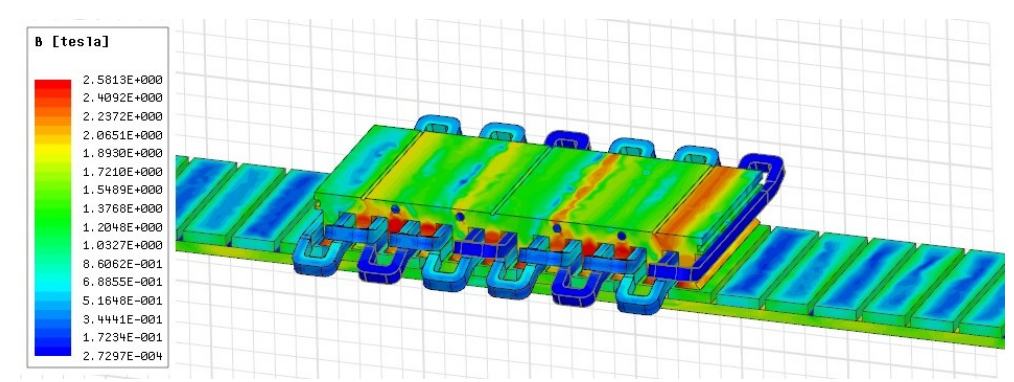

Figure 6. Magnetic field distribution at $0.8 \mathrm{~s}$.

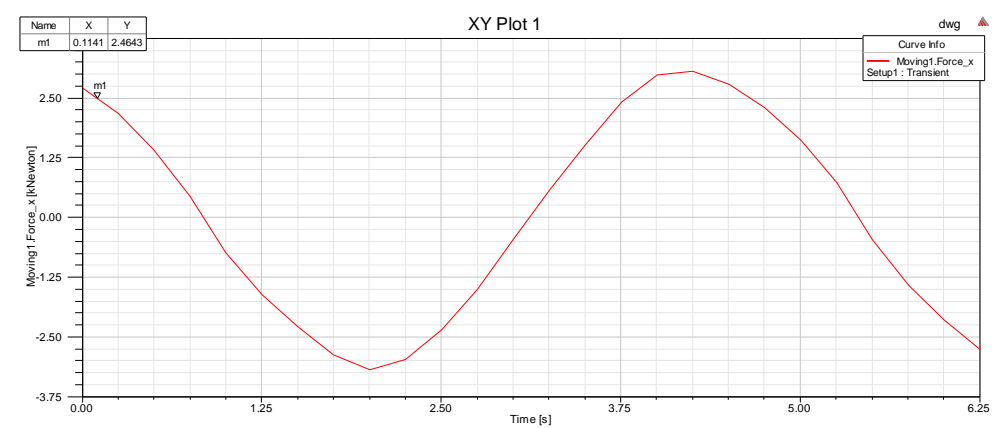

Figure 7. Thrust force profile versus time.

\section{Motor Prototype and Experimental Work}

In the electromagnetic FEA, the thrust force in $\mathrm{x}$-axis was calculated approximately as $2.5 \mathrm{kN}$. For manufacturing, y-axis force also had to be taken into account. The mechanical system was designed based on FEA results. A bearing was selected with $25-\mathrm{kN}$ limit set in the whole system and connected to armature by the pivot pin holes. First, the armature part was manufactured by using M36/29G, and it was laminated from electric steel. With the help of the pivot pins and welding grooves, the primary part was assembled. Second, the secondary part implementation with linear bearing and magnets gluing were carried out. In addition, a $2.8-\mathrm{mm}$ horizontal gap between magnets for nonmagnetic distance was used. In Figures 8 and 9, some manufacturing steps and test system of linear BLDC motor are illustrated. The back-iron with magnet assembly, the prototyped linear BLDC motor, armature windings and experimental test bed block schema are shown in Figures 8a-c and 9, respectively. Moreover, the experimental waveforms for the phase-a back-emf and current are shown in Figure 10. The permissible phase current and maximum phase current were measured as 45 and $90 \mathrm{~A}$, respectively.

The position resolution of the motor was measured as $250 \mu \mathrm{m}$ using a linear ruler in the experiments. Thus, a very high ratio of compliance with the reference displacement value was obtained in the displacement tests. The continuous thrust force was calculated as $2.5 \mathrm{kN}$, the maximum thrust force as $3.12 \mathrm{kN}$, but a current limiter ( $45 \mathrm{~A})$ was used for preventing overheating. The attraction force for the velocity of $0.48 \mathrm{~m} / \mathrm{s}$ was calculated as nearly ten times the thrust force. Due to the DC source limitations and the required maximum speed, the terminal voltage was assigned as $33.6 \mathrm{~V}$ and the terminal current was limited at $45 \mathrm{~A}$. The efficiency of the motor was calculated as $92.3 \%$ for continuous armature motion in the analysis, which is not the design case. Although the motor is designed for a short stroke application where the efficiency is no longer a performance criterion, a theoretical efficiency can be defined if the motor is subjected to a continuous motion application. Moreover, the force-to-air gap area was calculated as $17.12 \mathrm{~N} / \mathrm{cm}^{2}$, the force density as $0.613 \mathrm{kN} / \mathrm{kg}$ (only active part) and the cost-to-weight as $28.34 \$ / \mathrm{kg}$. 


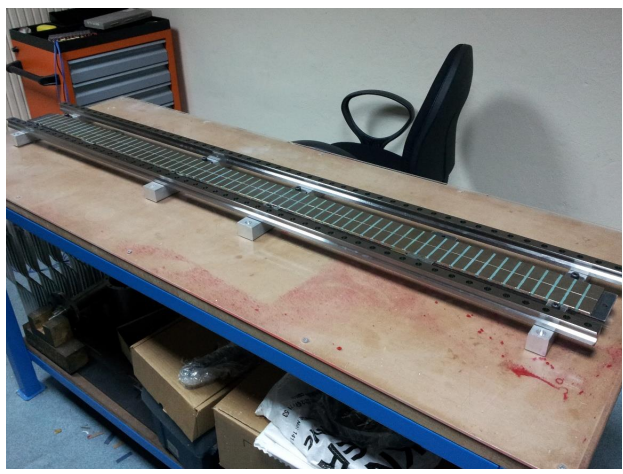

(a) Back iron with magnets.

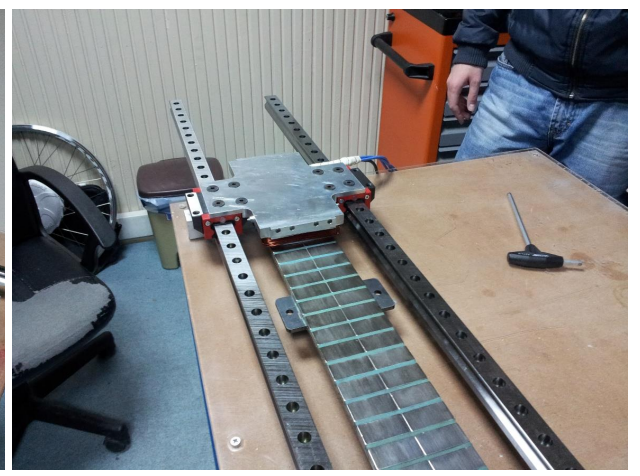

(b) Manufactured linear BLDC motor.

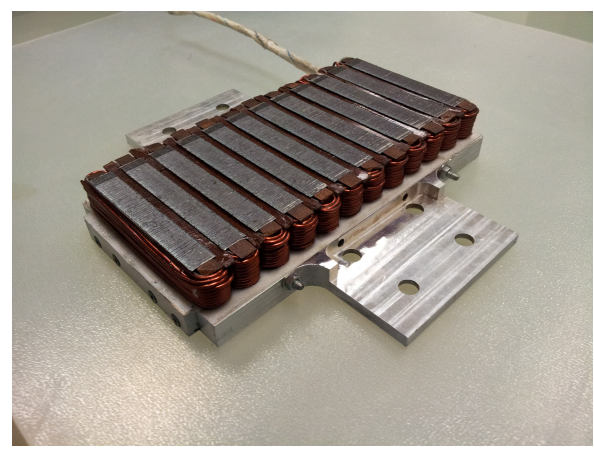

(c) Armature structure.

Figure 8. Manufacturing steps of linear BLDC motor.

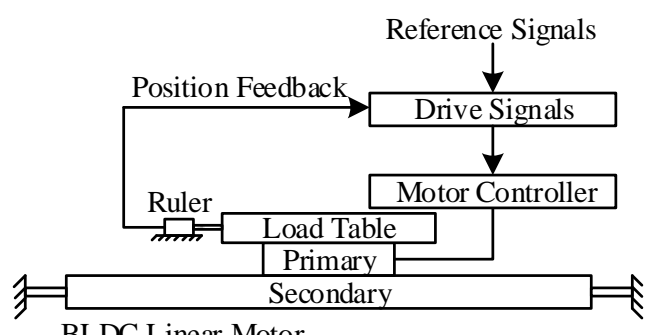

BLDC Linear Motor

Figure 9. Experimental test bed block schema.

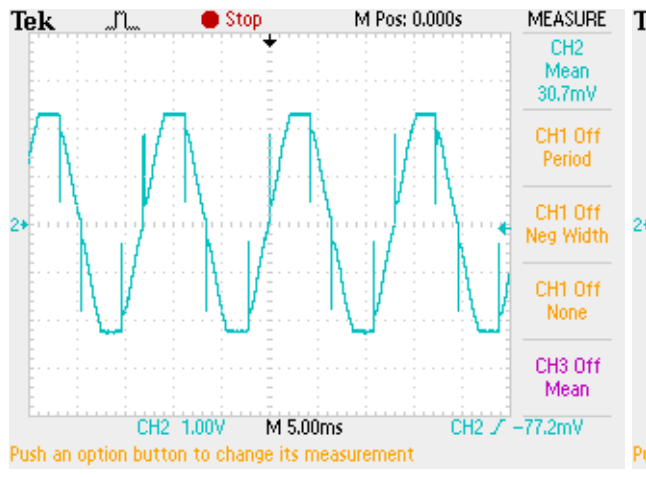

(a) Phase-a back-emf waveform.

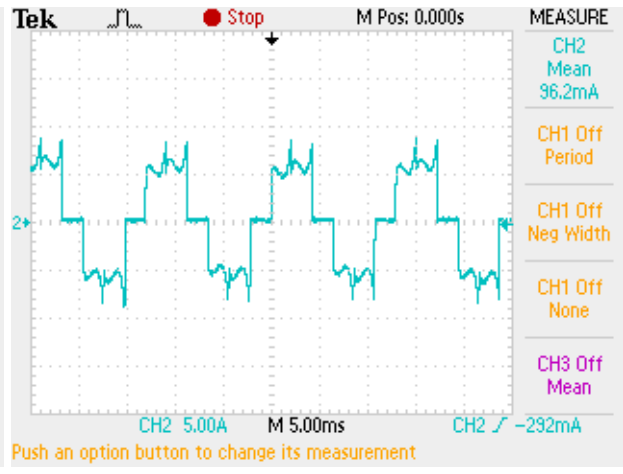

(b) Phase-a current waveform.

Figure 10. Experimental results for continuous motion.

To demonstrate the performance of the manufactured linear BLDC motor, tests were performed by taking the seismic waves which occurred in the 1999 Kocaeli earthquake as a reference. With the 
linear BLDC motor driver, a control algorithm with position, speed and current control loops was developed. As shown in Figure 11a, acceleration tests were performed by applying the seismic waves in a period of $33.8 \mathrm{~s}$ which reflect the mentioned earthquake. The dynamic speed response to the demanded wave of manufactured motor is shown in Figures 12a and 13a shows the displacement. Because the linear ruler used is of high-resolution and the linear motor is designed for the seismic shake table, a nearly $90 \%$ agreement with the computer-based analyses is achieved. Figures $11 \mathrm{~b}, 12 \mathrm{~b}$ and $13 \mathrm{~b}$ show the errors of the acceleration, speed and displacement, respectively. As can be seen in the related figures, the error values are admissible for the proper operation of the seismic shake system.

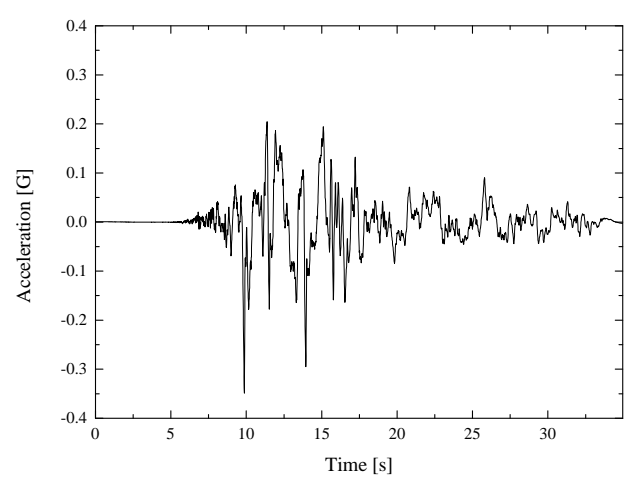

(a) Acceleration versus time graph.

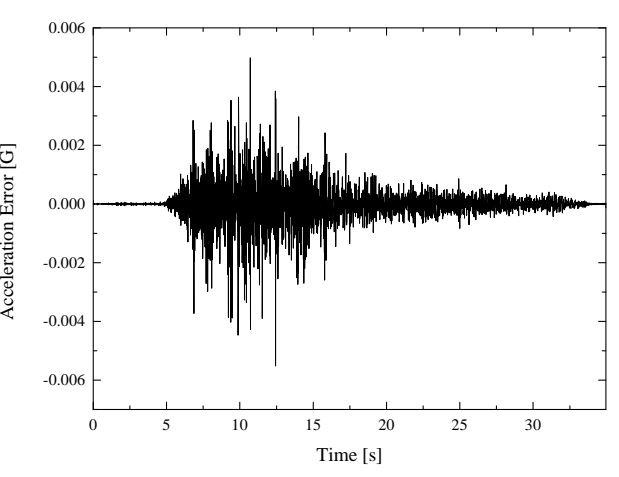

(b) Acceleration error versus time graph.

Figure 11. Seismic shake table experimental results for the 1999 Kocaeli earthquake reference seismic waves.

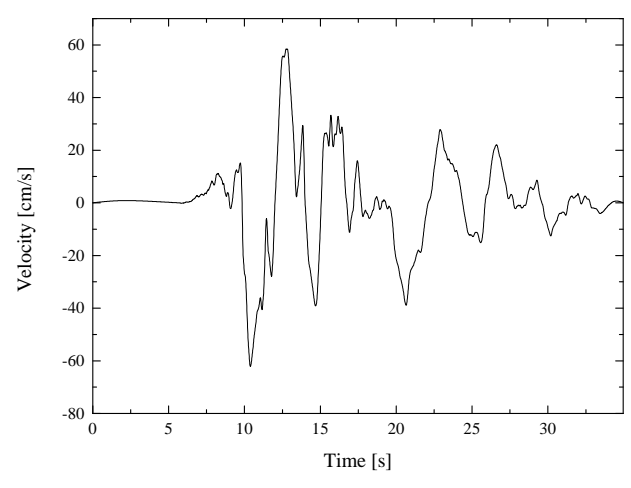

(a) Velocity versus time graph.

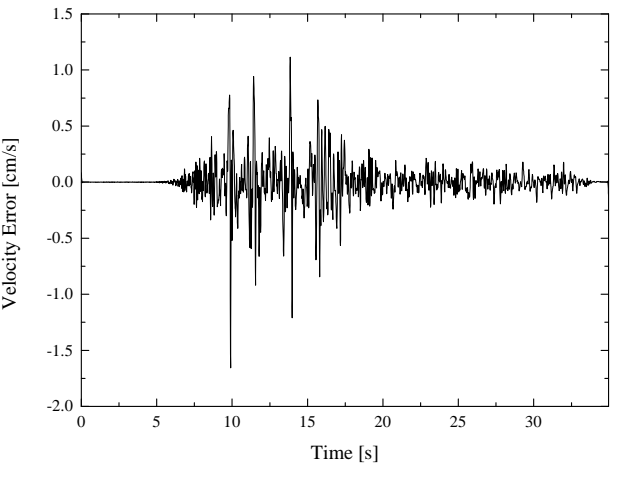

(b) Velocity error versus time graph.

Figure 12. Seismic shake table experimental results for the 1999 Kocaeli earthquake reference seismic waves.

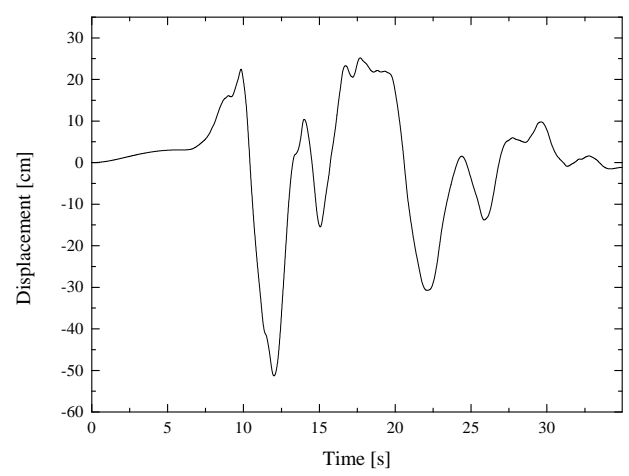

(a) Displacement versus time graph.

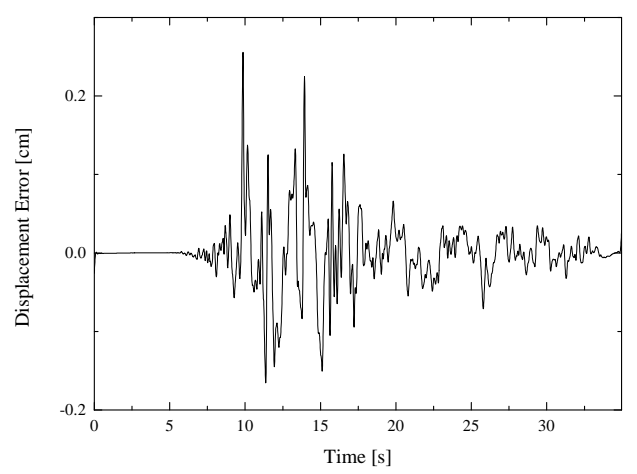

(b) Displacement error versus time graph.

Figure 13. Seismic shake table experimental results for the 1999 Kocaeli earthquake reference seismic waves. 


\section{Conclusions}

The main purpose of this paper is to provide a design approach for linear BLDC motors applied to seismic shake tables. With the developed approach, the initial design values are defined by taking into account all application requirements and material constraints. The electrical and mechanical parameters of the linear BLDC motor are determined with reference to these computed values. For seismic shake tables, the optimal values of acceleration, displacement and dynamic force are essential. First, the 1999 Kocaeli earthquake is investigated to find the parameters of the scaled seismic shake table that are driven by the designed motor. The accuracy of the design approach required for a seismic shake table was successfully demonstrated through the tests performed. The 2D analysis was properly used for the approximate calculation of the stroke force, while the $3 \mathrm{D}$ analysis provided the more detailed solutions of the whole motor structure.

Author Contributions: O.U. conceived the idea of the research, participated in all of the study phases and provided guidance and supervision. O.C.K. developed software and wrote the original draft. M.S.M. performed FEM analysis. All authors have contributed significantly to this work. All authors have read and agreed to the published version of the manuscript.

Funding: This research received no external funding.

Conflicts of Interest: The authors declare no conflict of interest.

\section{References}

1. Song, L.; Wu, J.; Bao, Y. Linear Permanent Magnet Motor Blend Brake System Simulation for Electromagnetic Launcher. In Proceedings of the 12th World Congress on Intelligent Control and Automation, Guilin, China, 12-15 June 2016.

2. Wen, C. Research on improved permanent-magnet linear synchronous motor for direct-drive application. IEEE Trans. Magn. 2019, 55, 8107007. [CrossRef]

3. Egami, T.; Tsuchiya, T. Disturbance Suppression Control with Preview Action of Linear DC Brushless Motor. In Proceedings of the IFAC 12th Triennial World Congress, Sydney, Australia, 18-23 July 1993.

4. Jin, J.X.; Guo, Y.G.; Zhu, J.G. Principle and analysis of a linear motor driving system for HTS levitation applications. Physica C 2007, 460-462, 1445-1446. [CrossRef]

5. Luo, H.H.; Wu, J.; Chang, W.S. Minimizing thrust fluctuation in moving-magnet permanent-magnet brushless linear DC motors. IEEE Trans. Magn. 2007, 43, 1968-1972. [CrossRef]

6. Yu, E. Forced vibration testing of buildings using the linear shaker seismic simulation (LSSS) testing method. Earthq. Eng. Struct. Dyn. 2005, 34, 737-761. [CrossRef]

7. Shen, G. Experimental evaluation of acceleration waveform replication on electrohydraulic shaking tables: A review. Int. J. Adv. Robot. Syst. 2016, 13, 1-25. [CrossRef]

8. Cheshmehbeigi, H.M.; Afjei, E.; Nasiri, B. Electromagnetic design based on hybrid analytical and 3-D finite element method for novel two layers BLDC machine Prog. Electromagn. Res. 2013, 136, 141-155. [CrossRef]

9. Noorlandt, R.; Drijkoningen, G.; Dams, J.; Jenneskens, R. A seismic vertical vibrator driven by linear synchronous motors. Geophysics 2015, 80, 1MA-Z50. [CrossRef]

10. Huang, X.Z. Detent-force minimization of double-sided permanent magnet linear synchronous motor by shifting one of the primary components. IEEE Trans. Ind. Electron. 2020, 67, 180-191. [CrossRef]

11. Boduroglu, A. A new asymmetric planar v-shaped magnet arrangement for a linear PM synchronous motor. IEEE Trans. Magn. 2019, 55, 8105905. [CrossRef]

12. Liu, X.; Zhen, S.; Sun, H.; Zhao, H. A novel model-based robust control for position tracking of permanent magnet linear motor. IEEE Trans. Ind. Electron. 2020, 67, 7767-7777. [CrossRef]

13. Aleksandrov, S.R.; Overboom, T.T.; Lomonova, E.A. Design optimization and performance comparison of two linear motor topologies with PM-less tracks. IEEE Trans. Magn. 2018, 54, 18164344. [CrossRef]

14. Zeng, Z. Comparative study of two novel double-sided hybrid-excitation flux reversal linear motors with surface and interior PM arrangements. IEEE Trans. Magn. 2019, 55, 18670033. [CrossRef]

15. Cao, R.; Cheng, M.; Hua, W. Investigation and general design principle of a new series of complementary and modular linear FSPM motors. IEEE Trans. Ind. Electron. 2013, 60, 4536-5446. [CrossRef] 
16. Chung, M.J.; Gweon, D.G. Design optimization and development of linear brushless permanent magnet motor. Int. J. Control. Autom. Syst. 2003, 1, 351-357.

17. Minghu, Y.; Yuqiu, Z.; Xiao, L.; Yunyue, Y. Design Method and Analysis of Double-Side Air-Core Permanent Magnet Linear Servo Motor. In Proceedings of the International Conference on Electrical Machines and Systems, Incheon, Korea, 10-13 October 2010.

18. Mirsalim, M.A.; Doroudi, A.; Moghani, J.S. Obtaining the operating characteristics of linear induction motors: A new approach. IEEE Trans. Magn. 2002, 38, 7265198. [CrossRef]

19. Zhu, Y.; Cho, Y. Structure Selection of Permanent Magnet Linear Synchronous Motor for Ropeless Elevator System. In Proceedings of the 14th Biennial IEEE Conference on Electromagnetic Field Computation, Chicago, IL, USA, 9-12 May 2010.

20. Hsue, A.W.J.; Tan, M.T.; Ke, S.H. Comparison on linear synchronous motors and conventional rotary motors driven Wire-EDM processes. J. Mater. Process. Technol. 2007, 1, 192-193. [CrossRef]

21. Nguyen, T.T.; Lazar, M.; Butler, H. A Computationally Efficient Commutation Algorithm for Parasitic Forces and Torques Compensation in Ironless Linear Motors. In Proceedings of the IFAC 7th Symposium on Mechatronic Systems, Leicerstershire, UK, 5-8 September 2016.

22. Seal, M.; Sengupta, M. Design, analysis and fabrication of a linear permanent magnet synchronous machine. Sadhanagy 2017, 42, 1419-1429. [CrossRef]

23. Chang, J.; Kang, D.H.; Viorel, I.A.; Larisa, S. Transverse flux reluctance linear motor's analytical model based on finite-element method analysis results. IEEE Trans. Magn. 2007, 43, 1201-1204. [CrossRef]

24. Rahideh, A.; Ghaffari, A.; Barzegar, A.; Mahmoudi, A. Analytical model of slotless brushless PM linear motors considering different magnetization patterns. IEEE Trans. Energy Convers. 2018, 33, 1797-1804. [CrossRef]

25. Abdou, G.; Tereshkovich, W. Experimental comparison of dynamic FEA results of a permanent magnet brushless DC linear motor. Int. J. Comput. Integr. Manuf. 2000, 13, 214-224. [CrossRef]

26. Ozturk, S. A study on the variations of recent seismicity in and around the Central Anatolian region of Turkey. Phys. Earth Planet. Int. 2020, 301, 106453. [CrossRef]

27. Senol, S.; Ustun, O. Design and analysis of a sub-fractional slot concentrated winding BLDCM with unequal tooth widths. Int. J. Appl. Electromagn. Mech. 2012, 39, 859-864. [CrossRef]

28. Lu, J. Research on a linear permanent magnet brushless DC motor for electromagnetic catapult. IEEE Trans. Plasma Sci. 2015, 43, 2088-2094. [CrossRef]

29. Liu, Y.; Zhang, X.; Niu, S. A permanent magnet linear motor with complementary flux and its optimization. IEEE Trans. Magn. 2019, 55, 8201005. [CrossRef]

30. Hanselman, D.C. Brushless Permanent Magnet Motor Design, 2nd ed.; The Writers' Collective: Columbus, $\mathrm{OH}$, USA, 2003; ISBN 978-1932133639.

31. Hendershot, J.R.; Miller, T.J.E. Design of Brushless Permanent Magnet Motors, 1st ed.; Clarendon Press: Gloucestershire, UK, 1995; ISBN 978-0198593898.

32. Min, S.G.; Sarlioglu, B. Analytical calculation of back EMF waveform for linear PM motors in slotted and slotless structures. IEEE Trans. Magn. 2017, 53, 8112910. [CrossRef]

Publisher's Note: MDPI stays neutral with regard to jurisdictional claims in published maps and institutional affiliations.

(C) 2020 by the authors. Licensee MDPI, Basel, Switzerland. This article is an open access article distributed under the terms and conditions of the Creative Commons Attribution (CC BY) license (http:/ / creativecommons.org/licenses/by/4.0/). 